Endocrine Disorders

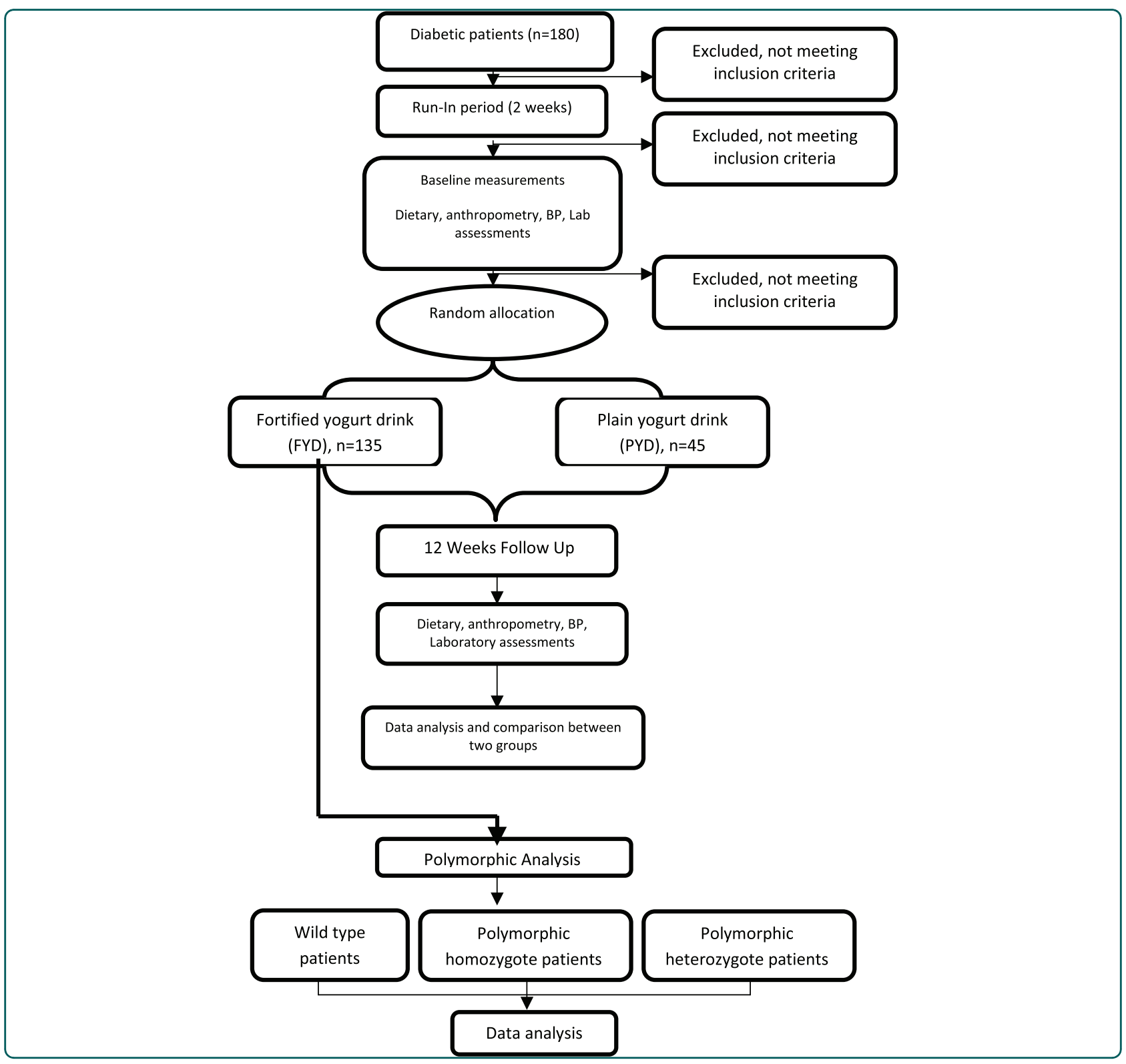

Efficacy of vitamin D3-fortified-yogurt drink on anthropometric, metabolic, inflammatory and oxidative stress biomarkers according to vitamin $D$ receptor gene polymorphisms in type 2 diabetic patients: a study protocol for a randomized controlled clinical trial

Shab-Bidar et al. 


\title{
Efficacy of vitamin D3-fortified-yogurt drink on anthropometric, metabolic, inflammatory and oxidative stress biomarkers according to vitamin D receptor gene polymorphisms in type 2 diabetic patients: a study protocol for a randomized controlled clinical trial
}

\author{
Sakineh Shab-Bidar ${ }^{1}$, Tirang R Neyestani ${ }^{2^{*}}$ and Abolghassem Djazayery ${ }^{1 *}$
}

\begin{abstract}
Background: Development of type 2 diabetes mellitus (T2DM) is determined by the interactions of genetic and environmental factors. This study was designed to evaluate the possible role of VDR single nucleotide polymorphisms (SNPs) on different aspects of diabetic host response (anthropometric, metabolic, oxidative stress and inflammatory) to daily intake of vitamin D through fortified yogurt drink for 12 weeks.

Methods/Design: This study comprises two parts: (i) a case-control study; and (ii) an intervention trial. In the first part, VDR polymorphisms (Taq1, Fokl, Apa1, Bsm1, and Cdx2) are determined in 350 T2DM patients and 350 non-diabetic subjects. In the second part, the possible effects of daily intake of two servings of vitamin D3-fortified yogurt drink (FYD; $500 \mathrm{IU}$ vitamin $\mathrm{D} / 250 \mathrm{~mL}$ ) on some selected metabolic (including insulin resistance), inflammatory and oxidative stress biomarkers in 135 T2DM patients are assessed. To relate the resulted changes in the biomarkers to vitamin D replenishment, another group of diabetic patients $(n=45)$ are also included in the study who receive 2 servings of plain yogurt drink (PYD) a day. The primary outcome is serum level of $25(\mathrm{OH}) \mathrm{D}$, which it is expected to be elevated only in FYD group. Secondary outcomes include improvements in glycemic, metabolic, inflammatory and oxidative stress biomarkers in FYD group compared to PYD group. Three VDR Fokl polymorphisms are determined only in FYD group followed by comparison of changes in the biomarkers among these genotypic variants.

Discussion: The present study, at least in part, elucidates the discrepancies in the results of different vitamin D-diabetes studies pertaining to the genetic variations of the population. If VDR polymorphisms are found to influence the response to our intervention, then knowing distribution of VDR polymorphisms in both diabetic and non-diabetic populations can give a picture of the proportion of the community in whom up to $1000 \mathrm{IU} / \mathrm{d}$ vitamin $\mathrm{D}$ may not be effective enough to improve insulin resistance and related morbidities. Therefore, they should ideally receive further nutritional support according to their genotype.
\end{abstract}

Trial Registration: ClinicalTrials.gov: NCT01236846

Keywords: vitamin D, vitamin D receptor, polymorphism, type 2 diabetes, study protocol

\footnotetext{
* Correspondence: neytr@yahoo.com; jazaiers@sina.tums.ac.ir

'Department of Nutrition and Biochemistry, School of Public Health, Tehran University of Medical Sciences (TUMS), Tehran, Iran

2Laboratory of Nutrition Research, National Research Institute and Faculty of Nutrition and Food Technology; Shahid Beheshti University of Medical

Sciences (SBUM), Tehran, Iran

Full list of author information is available at the end of the article
} 


\section{Background}

Type 2 diabetes mellitus (T2DM) is a global epidemic costly condition [1]. Individuals with diabetes sustain reduction in quality of life, and high prevalence of mortality [2].

Development of T2DM is determined by the interactions of genetic and environmental factors [3,4]. Most, if not all, genetic influences have a polymorphic nature $[5,6]$. A number of loci have been studied so far to explain the genetic susceptibility to T2DM. An Example is genes associated with glucokinase, hepatocyte nuclear factors, insulin promoter factors, possibly the insulin and insulin receptor genes and mitochondrial genes [7]. Among interesting, and less studied, diabetes-related genes are those associated with vitamin D metabolism.

Apart from its calcemic effects, vitamin D is now known to have many non-calcemic functions through which it may have some role in several human pathologies including some forms of cancers [8], autoimmune disorders [9], obesity [10], metabolic syndrome [11] and both types 1 and 2 diabetes $[12,13]$, among the others. Animal studies have shown impaired insulin secretion [14] and action $[15,16]$ in vitamin D deficiency. Though vitamin D replenishment of type 2 diabetics has been shown to improve inflammatory biomarkers and glycemic control [17-23], some studies failed to demonstrate these beneficial effects $[24,25]$. The reasons for these discrepancies in results could be numerous including sample size, duration and mode of intervention (supplementation, injection, fortification, or...) and dosages used, baseline values of 25(OH)D and also of the other variables (glucose, lipids and so on), method of vitamin D assessment (RIA, CPBA, CL or HPLC) and finally genetic makeup of the study population.

The active form of vitamin $\mathrm{D}$ acts through a specific vitamin D receptor (VDR) [26]. Allelic differences in the VDR gene may contribute to the genetic predisposition to certain diseases [10]. Research findings on associations among VDR polymorphisms, vitamin D stats, T2DM and glycemic status have not been unanimous; some confirmed such relations [18] and some did not [25]. Nevertheless, as VDR has been recently found on pancreatic beta cells [24], it is plausible that genetic variants of the VDR gene may contribute to the development of T2DM. There is a mere paucity of controlled clinical trials on vitamin D and T2DM. On the other hand, the findings of a few trials have been inconsistent. Those studies mostly used either vitamin D injection (monthly or weekly high dose injection) $[27,28]$ or supplements $[16,29,30]$ (usually with dosages less than the amount believed to be sufficient [31]). In the present study we are going to use yogurt drink, which is an Iranian drink (Persian name: Doogh), for vitamin D fortification. Using fortified foodstuffs have the advantage of lower cost and higher compliance [32]. Considering the common nature of T2DM with obesity-induced insulin resistance and metabolic syndrome [33], two conditions with growing occurrence which may lead to T2DM [34], using vitamin D3-fortified yogurt drink, if proved to be effective in this study, can be encouraged as a preventive tool. This idea must be substantiated by further cohort studies.

This study was designed to evaluate the possible role of VDR single nucleotide polymorphisms (SNPs) on different aspects of diabetic host response (anthropometric, metabolic, oxidative stress and inflammatory) to daily intake of vitamin D through fortified yogurt drink for 12 weeks.

\section{Specific Aims}

This study comprises two parts. The first part aims to quantify the magnitude of association between any identified variants of the VDR gene and T2DM. A cross-sectional study is employed to compare distribution of each genotype of VDR polymorphisms in 350 type 2 diabetic adults and 350 non-diabetic controls. The second part is outlined to compare within- and between-polymorphic group variations of host response to daily intake of vitamin-D3-fortified yogurt drink in terms of anthropometric, metabolic, inflammatory and oxidative stress markers.

\section{Part 1}

\section{Primary Objectives}

To determine distribution of VDR gene polymorphism genotypes (Taq1, FokI, apa1, Bsm1, Cdx1) in T2DM patients and non-diabetic volunteers and to compare between these two groups

\section{Secondary Objectives}

To determine distribution of VDR gene polymorphism haplotypes (Taq1, FokI, Apa1, Bsm1, Cdx2) in T2DM patients and non-diabetic controls and to compare between these two groups

\section{Hypothesis}

(i) There is a difference in prevalence of vitamin D receptor gene polymorphisms between diabetics and non-diabetic controls

(ii) There is a difference in prevalence of vitamin D receptor gene polymorphism haplotypes between diabetics and non-diabetic controls

\section{Part 2 study \\ Primary Objectives}

To compare within- and between-polymorphic group variations in circulating $25(\mathrm{OH}) \mathrm{D}$ in diabetic subjects and also between diabetics and non-diabetic subjects. 


\section{Secondary objectives}

(i) To compare within- and between-polymorphic group variations in anthropometric, metabolic, inflammatory and oxidative stress biomarkers

(ii) To conduct an exploratory analysis of changes in mean of anthropometric, metabolic, inflammatory and oxidative stress biomarkers in FYD group among subgroups defined by genotypes of each VDR polymorphisms.

\section{Hypothesis}

(i) Daily consumption of vitamin D3-fortified-yogurt drink improves serum $25(\mathrm{OH}) \mathrm{D}$ in type 2 diabetic patients.

(ii) Daily consumption of vitamin D3-fortified-yogurt drink improves biomarkers of anthropometric, metabolic, inflammatory and oxidative stress in type 2 diabetes patients.

(iii) Response to daily consumption of vitamin-D3-fortified yogurt drink differ between VDR polymorphic variant groups

\section{Methods/Design \\ Part 1 \\ Participants}

A case-control study is designed to compare VDR gene polymorphism distribution between T2DM and age-, sex- and body mass index (BMI)-matched non-diabetic subjects. T2DM patients are recruited from two centers; Iranian Diabetes Society and Gabric Diabetes Society, both located in Tehran. Diabetic subjects are recruited either by attending the classes held at the two centers and verbal invitation or through phone call. Non-diabetic controls are enrolled from school teachers, workers of Tehran or Shahid Beheshti Universities and Pegah Dairy Companies, all located in Tehran.

Full information on the study design and objectives of the study is given to all participants before they sign an informed written consent.

\section{Sample Size}

For observational study the sample size needed to obtain $90 \%$ power at a $5 \%$ significance level with an equal number of case and controls for the chi-square test on genotypes, is 350 at each group of cases and controls. The sample size is calculated using the software Quanto: http://hydra.usc.edu/gxe/.

\section{Blood sampling}

Fasting venous blood samples are collected into tubes either with or without anticoagulant (ethylene diamine tetra-acetate, EDTA). The anticoagulated tube is used to extract genomic DNA while the sera from clot samples are analyzed for glucose and lipids. Further information about blood sampling and genotyping are in part 2 study in detail.

\section{Variables}

Information on demographic, medical history, physical activity, duration of direct sun exposure and smoking habits are gathered using questionnaires and face-toface interview. Anthropometric measures are taken in the same meeting. Table 1 shows the study variables.

\section{Value of results}

This is the first study on the distribution of VDR SNPs among type 2 diabetics and their possible relations to the particular phenotypes in Iran. These data assist both to the better understanding of vitamin D-T2DM interrelationships and to the preventive programs.

\section{Part 2}

This is a 3-month randomized controlled clinical trial (RCT) in which T2DM patients aged 30-60 years are enrolled. The study design is presented in Figure 1.

\section{Setting}

The possible effects of daily intake of two servings of vitamin D3-fortified yogurt drink on some selected metabolic (including insulin resistance), inflammatory and oxidative stress biomarkers in T2DM patients $(\mathrm{n}=$ 135) are assessed. To relate the resulted changes in the biomarkers to vitamin $\mathrm{D}$ replenishment, another smaller group of diabetic patients $(\mathrm{n}=45)$ are also included in the study who receive 2 servings of plain yogurt drink a day. To minimize endogenous vitamin $\mathrm{D}$ synthesis, the entire intervention is confined to cold seasons (fall and winter) of the year. The RCT is conducted collaboratively by National Nutrition and Food Technology Research Institute (NNFTRI) and Tehran University of Medical Sciences (TUMS) in Tehran, the capital of Iran.

\section{Participants}

T2DM patients are recruited from Iranian Diabetes Society or Gabric Diabetes Society as described in the first part of the study. Volunteers are invited to attend Laboratory of Nutrition Research at NNFTRI while they are fasting. Data gathering, bleeding and urine sampling all are done during 07.30 and $10.00 \mathrm{am}$.

\section{Inclusion criteria}

1. Having type 2 diabetes

2. Willingness to participate

3. BMI between 25 to $35 \mathrm{~kg} / \mathrm{m}^{2}$

4. Age: $30-60$ years old

5. No use of any vitamin, dietary, herbal or omega-3 supplements since at least 3 months to and during the intervention period

\section{Exclusion criteria}

1. History of cardiovascular, gastrointestinal, renal, and other endocrinological diseases

2. Subjects receiving vitamin $\mathrm{D}$, omega-3 or other types of dietary supplements 
Table 1 Study measures

\begin{tabular}{ll}
\hline Variable & Methods \\
\hline General data & Questionnaire \\
\hline Demographic data & Questionnaire \\
\hline Medical history & Questionnaire \\
\hline Sun exposure & \\
\hline Anthropometric and clinical data & Stadiometer, digital scale (Seca 840, Germany) \\
\hline Height, weight, waist and hip circumference & A digital sphygmomanometer (BC08, Beurer, Germany). \\
\hline Blood pressure & \\
\hline Blood data & Pars Azmoon, Tehran, Iran \\
\hline Fasting plasma glucose, lipid profile & Mythic, Orphe'e, France \\
\hline Complete blood cell count & PCR-RFLP, Corbett Rotor-Gene 6000 instrument (Corbett Life Science) \\
\hline VDR gene polymorphisms & \\
\hline
\end{tabular}

3. Pregnancy or lactation

4. Treatment with insulin

5. Treatment for weight reduction

6. Treatment for reducing serum cholesterol

\section{Sample Size}

Based on data on serum 25(OH)D changes from other studies [35], to achieve 1 standard deviation difference in circulating $25(\mathrm{OH}) \mathrm{D}$ with two-sided alpha of 0.05 and a beta of 0.2 after a 12 -week intervention period, the sample size was calculated 40 individuals per treatment group. Considering 3 polymorphic variant groups and one control group which receives plain yogurt drink, 160 subjects are needed. Allowing for $10 \%$ attrition over 12 weeks of intervention, a total of 180 subjects are required.

\section{Run-in}

On the first visit and following completion of the questionnaires, all participants are given some general information on diabetic diet, based on American Dietetic Association (ADA) guidelines [36], with special focus on fruits, vegetables and dairy intakes. Patients are instructed not to change their usual physical activity and to include 2-3 exchanges of fruits, 2 exchanges of vegetables and 2-3 exchanges of low-fat milk exchanges in their daily diet for the next 2 weeks (run in period).

\section{Randomization/Blinding}

After run-in period, participants are assigned randomly to one of the treatment groups of either fortified yogurt drink (FYD, $\left.\mathrm{n}_{1}=135\right)$ or plain yogurt drink (PYD, $\mathrm{n}_{2}=$ 45) using permuted blocks of random numbers allocation method. Letter codes A and B are used to identify two groups, respectively. Yogurt drinks are identical in color, size, taste and packaging. Therefore, participants are not aware of their group, neither are all the interviewers and laboratory staff. However, the main investigators could not be technically blind to the identity of the letter codes.
The randomization and labeling process are audited halfway through the study by an observer to find if it is robust, accurate and able to maintain blinding of participants.

\section{Intervention}

Yogurt drinks are either plain (PYD; containing $170 \mathrm{mg}$ calcium and no vitamin $\mathrm{D} / 250 \mathrm{~mL}$ ) or vitamin $\mathrm{D}_{3}$-fortified (FYD; containing $170 \mathrm{mg}$ calcium and $500 \mathrm{IU}$ vitamin $\mathrm{D}_{3} / 250 \mathrm{~mL}$ ). Participants are instructed to consume a bottle of yogurt drink with both lunch and dinner, i.e. $500 \mathrm{~mL} / \mathrm{d}$ equaling $1000 \mathrm{IU}$ vitamin $\mathrm{D}_{3}$ a day in FYD group. The intervention period is 12 weeks. Consumption of $1000 \mathrm{IU} / \mathrm{d}$ vitamin $\mathrm{D}$ is believed to be safe and effective to increase circulating $25(\mathrm{OH}) \mathrm{D}[13,37,38]$. Participants are given yogurt drinks in 30-bottle packs, which are enough for 2 weeks. All subjects are visited biweekly to both assess their compliance and provide them with yogurt drinks for the next two weeks. Blood pressure, anthropometric, dietary, body fat and laboratory evaluations are preformed both before and after intervention. Data comparison are made between PYD and FYD groups and also, in FYD group, among VDR polymorphic groups.

\section{Compliance}

All participants are given a pamphlet on "instructions to use yogurt drinks" together with a "yogurt drink consumption table" comprised of 28 empty boxes for each week. Subjects are instructed to mount the table in an exposed place (preferably on refrigerator) and to tick each box after consumption a yogurt drink with each meal. Moreover, they are asked to bring the empty bottles back on their next visit. Compliance is evaluated by checking the consumption tables, counting the empty bottles, direct enquiry both on the biweekly visits and weekly follow-up phone calls.

\section{Quality control of product}

Composition (including vitamin $\mathrm{D}_{3}$ ) of the yogurt drinks are measured right after production, in the middle and end of the storage, to ensure the stability of the 


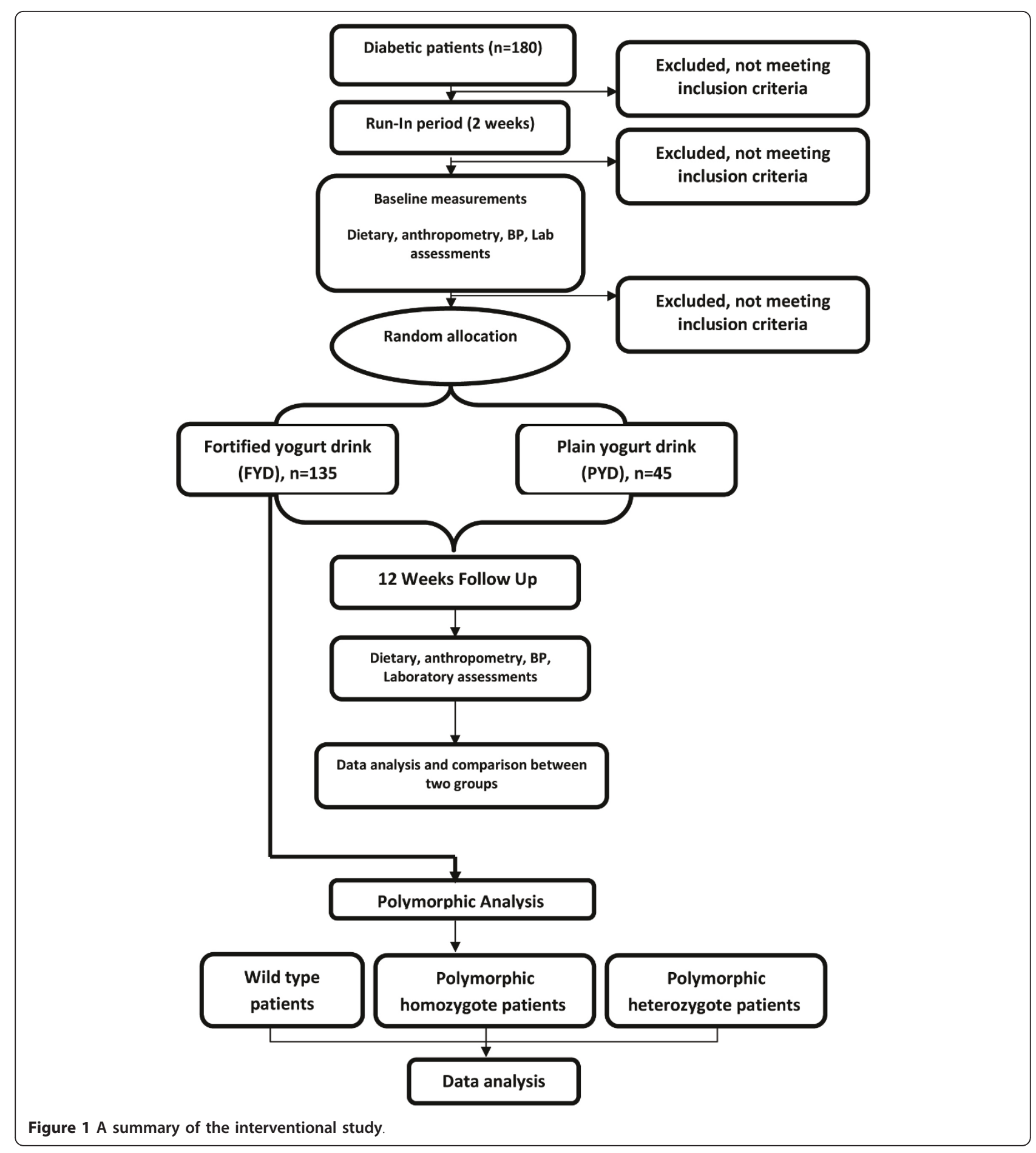

components, especially vitamin $\mathrm{D}$, in the product. The measurements are done by Maad Laboratory of Foods, Drinks and Cosmetics, accredited by the Deputy of Food and Drug of the Iranian Ministry of Health.

\section{Outcome Measurements}

Dietary assessment A semi-quantitative Food Frequency Questionnaire (sqFFQ) and 24-h dietary recall for 3 days (including a weekend day) are used for assessment of dietary intake.

Anthropometry and Blood Pressure Body weight is measured with light clothes without shoes using a digital scale (Seca 808, Germany) to the nearest of $0.1 \mathrm{~kg}$. Height is measured using a stadiometer (Seca, Germany) to the nearest of $0.1 \mathrm{~cm}$. BMI is calculated by dividing 
weight $(\mathrm{kg})$ per height $(\mathrm{m})$ square. Waist circumference (WC) is measured in the midpoint of the lowest rib and iliac crest in the end of expiration using a measuring tape to the nearest of $0.1 \mathrm{~cm}$

To measure blood pressure (BP), subjects are allowed to be in sitting position at least 10 minutes. $\mathrm{BP}$ is measured twice by a digital sphygmomanometer (BC08, Beurer, Germany). The average of the two measurements is considered as subject's BP.

Body Composition Analysis The percentage of body fat is evaluated using bioelectrical impedance analysis (Quadscan 4000 system, Bodystat, UK).

\section{Laboratory investigations}

All laboratory analyses are performed at the Laboratory of Nutrition Research, NNFTRI.

\section{Blood sampling and handling}

Twenty $\mathrm{mL}$ of fasting venous blood taken from all participants by phlebotomy is divided in three tubes: (i) a micotube with an anticoagulant, EDTA; (ii) a heparinized $15-\mathrm{mL}$ sterile capped plastic tube; and (iii) a clean glass test tube without anticoagulant. Of about $500 \mu \mathrm{L}$ EDTAblood sample in the microtube, $9 \mu \mathrm{L}$ is used for CBC. Heparinized blood sample is used for PBMC separation and culture while the clot blood samples are kept for $\sim 30$ at RT followed by centrifugation at $1500 \mathrm{~g}$ at RT. Sera thus recovered are transferred to clean micro-tubes in aliquots. One aliquot is used to determine fasting serum glucose (FSG) and lipid profile in the same day of bleeding while the other tubes are kept at $-80^{\circ} \mathrm{C}$ until the day of analysis.

\section{Hemoglobin and hematocrit}

Hemoglobin and hematocrit are measured as parts of complete blood cell count (CBC) test in the same day of blood sampling by a cell-counter system (Mythic, Orphee, France).

\section{Blood chemistry}

Fasting serum glucose (FSG), lipid profile including triglycerides (TG), total cholesterol, low-density lipoprotein cholesterol (LDL-C), and high-density lipoprotein cholesterol (HDL-C), alanine aminotransferase (ALT), aspartate aminotransferase (AST) and uric acid are determined using enzymatic methods. Serum total protein, albumin, calcium, phosphorous and magnesium are measured by colorimetric assays. All these tests are done by commercial kits (all from Pars Azmoon, Iran) using an auto-analyzer system (Selectra E, Vitalab, the Netherlands).

Glycated hemoglobin (HbA1c) is determined using colorometric method after an initial chromatographic separation (BioSystems, Spain).

Serum insulin levels are measured by immunoradiometric assay (IRMA) using a commercial kit (Biosource,
Belgium) and a $\gamma$-counter system (Gamma I, Genesys, USA).

Insulin resistance is evaluated by Quantitative Insulin Check Index (QUICKI) calculated as [39]:

QUICKI: 1/[log (insulin) $(\mu \mathrm{U} / \mathrm{mL})+\log$ (glucose) $(\mathrm{mg} / \mathrm{dL})]$

Serum 25(OH)D concentrations are measured by HPLC method as described elsewhere [40]. Serum intact parathyroid hormone (iPTH) (DRG, Germany) and osteocalcin (Biousource, Belgium) concentrations are determined using enzyme immunoassay (EIA).

In this study oxidative stress is evaluated by determination of serum glutathione, glutathione peroxidase, glutathione reductase, superoxide dismutase (all from Bender Medsystems, Austria), total antioxidant capacity (TAC) using colorometic method with ABTS reagent and bovine serum albumin as standard, as reported earlier [41] and malondialdehyde (MDA), as described originally [42] with some modifications [43].

Inflammatory status is evaluated using determination of highly sensitive C-reactive protein (hsCRP) (immunoturbidometric assay, Pars Azmoon, Iran), serum amyloid A (SAA), endothelin-1 (both from IBL, Germany), E-selectin and matrix metalloproteinase (MMP)-9 (both from e-Bioscience, Austeria).

\section{Urinary tests}

Urinary sodium and potassium are measured by flame photometry (Corning 480; Corning Ltd, Halstead, Essex, UK). Urinary albumin and Creatinine are determined by immunoturbidometric and colorometic methods, respectively (both from Pars Azmoon, Iran) with the aid of an auto-analyzer (Selectra E, Vitalab, the Netherlands).

\section{PBMCs culture}

Peripheral blood mononuclear cells (PBMC) were separated using Ficoll-hypaque gradient density centrifugation and cultured as described elsewhere [44] with minor modifications. In this study, $\sim 10^{6}$ cells are transferred to a culture well in a 6-well cell culture plate (Greiner bio-one, Germany), each well containing 1\% phytohemmaglutinin (PHA) (Gibco), $100 \mathrm{ng} / \mathrm{mL}$ lipopolysaccharide (LPS) (Gibco), $100 \mathrm{U} / \mathrm{mL}$ penicillin $\mathrm{G}$ and $10 \mathrm{ng} / \mathrm{mL}$ streptomycin (both from Sigma-Aldrich) in a total volume of $2 \mathrm{~mL}$ RPMI 1640. PBMC culture is performed in triplicate.

\section{Cytokine assay}

Concentrations of interleukin (IL)-2, IL-4, IL-6, IL-10 and tumor necrosis factor (TNF) $-\alpha$ (all from Bender Medsystems, Austria) are determined in PBMCs culture supernatant. All EIA tests are performed with the aid of a microplate reader (Statfax 3200, Awareness, USA).

\section{DNA extraction}

Whole blood collected in a microtube containing $20 \mu \mathrm{L}$ 7\% EDTA are processed using Genet Bio DNA Isolation 
Kit (PrimePrepth, South Korea) following the procedures detailed in the kit to extract genomic DNA. Stock DNA is stored at -20 in a linked anonymized format, with codes held by principal investigators.

\section{DNA genotyping}

The VDR genotypes at BsmI, TaqI, ApaI, FokI and $C d x-2$ SNP sites are determined using polymerase chain reaction (PCR)-restriction fragment length polymorphism (RFLP) analysis as described below. We use a gradient palm-cycler (Corbett Research, Australia) for PCR amplification. The purified primers (Fermentase) and Premixes (Cinnagen) are purchased. Specific primers are selected and validated for SNPs (table 2) [45-47]. We use BLAST search (http://www.ncbi.nlm. nih.gov/BLAST) to check the specificities and homology percent of primers for the VDR sequence. All primers show $99 \%$ homology to the sequence in specific region of the VDR gene.

\section{Data management}

For the better quality and accuracy of data, real time data entry is ensured. We use manual checking of frequencies during data entry. For primary analysis, alphabetical codes for groups are used still blinded to the real group identity.

\section{Statistical analyses}

Data are expressed as mean \pm SD. Normality of data distribution is evaluated using Kolmogrov-Smirnov. Comparison of data between two groups is done by either student $t$ test (normal distribution) or MannWhitney U (not normal distribution).

Genotype distribution of the 5 VDR SNPs in the study population is evaluated for Hardy-Weinberg equilibrium by Chi square test. Odds ratios (OR) are given with 95\% confidence intervals (CI). Haplotypes frequencies and distributions are estimated with a program based on $\mathrm{EH}$ (estimating haplotypes)[48]. Haplotypes are compiled as combinations of the 3 SNPs (BsmI, TaqI, ApaI).

The differences in distribution of the biomarkers among polymorphic variant groups are compared by analysis of variance (ANOVA) and, in the case of significant difference, Tukey's post hoc analysis. A p value $<0.05$ is considered significant. Correlation between two sets of data is evaluated using either Pearson (normal distribution) or Spearman (not normal distribution) equations. Multiple linear regression modeling is used to identify the contributions of each independent variable to the variation of response to vitamin D supplementation.

\section{Data Validation}

Data cleaning takes place by a series of logical checks on the electronic data. Discrepant records are checked with the source documents and the database is amended, if necessary.

\section{Ethical issues}

The study protocol has been approved by the NNFTRI (No. 035360), Shahid Beheshti University of Medical Science, and by Tehran University of Medical Sciences (TUMS) (No.10533) Ethical committees.

Table 2 VDR polymorphisms and PCR-RFLP information

\begin{tabular}{|c|c|c|c|c|c|c|c|c|c|c|}
\hline SNP & Localization & $\begin{array}{l}\text { Base } \\
\text { change }\end{array}$ & Nomenclature & $\begin{array}{l}\text { Forward primer/ } \\
\text { reverse primer }\end{array}$ & Amplicone & $\begin{array}{l}\text { Restriction } \\
\text { site }\end{array}$ & $\begin{array}{l}\text { Digestion } \\
\text { fragments }\end{array}$ & Genotype & $\begin{array}{l}\text { Restriction } \\
\text { enzyme }\end{array}$ & Reference \\
\hline Fokl & Exon 2 & $C / T$ & $\begin{array}{l}\mathrm{FF} \\
\mathrm{Ff} \\
\mathrm{ff}\end{array}$ & 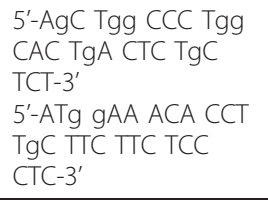 & 265 & $\begin{array}{l}C C \\
C T \\
T T\end{array}$ & $207-60$ & $\begin{array}{l}\text { mut } \\
\text { ht } \\
\text { wt }\end{array}$ & Fokl & [45] \\
\hline Bsml & Intron 8 & $\mathrm{G} / \mathrm{A}$ & $\begin{array}{l}\mathrm{BB} \\
\mathrm{Bb} \\
\mathrm{bb}\end{array}$ & $\begin{array}{l}5^{\prime}-g g C \text { AAC CTg AAg } \\
\text { ggA gAC gTA-3' } \\
\text { 5'-CTC TाT ggA CCT } \\
\text { CAT CAC CgA C-3' }\end{array}$ & 461 & $\begin{array}{l}\mathrm{AA} \\
\mathrm{GA} \\
\mathrm{GG}\end{array}$ & $258-253$ & $\begin{array}{l}\text { mut } \\
\text { ht } \\
\text { wt }\end{array}$ & Mva 1269| & [46] \\
\hline Taql & Exon 9 & $\mathrm{~T} / \mathrm{C}$ & $\begin{array}{l}\mathrm{T} \\
\mathrm{Tt} \\
\mathrm{tt}\end{array}$ & $\begin{array}{l}\text { 5'-CAg AgC ATg gAC } \\
\text { Agg gAg CAA g-3' } \\
5^{\prime}-g C A \text { ACT CCT CAT } \\
\text { ggC TgA ggT CTC A- } \\
3^{\prime}\end{array}$ & 740 & $\begin{array}{l}\text { TT } \\
\text { TC } \\
\text { CC }\end{array}$ & $\begin{array}{l}495-245- \\
290-205\end{array}$ & $\begin{array}{l}\text { wt } \\
\text { ht } \\
\text { mut }\end{array}$ & Taql & [45] \\
\hline Apal & Intron 8 & $\mathrm{G} / \mathrm{T}$ & $\begin{array}{l}\text { AA } \\
\text { Aa } \\
\text { aa }\end{array}$ & $\begin{array}{l}\text { 5'-CAg AgC ATg gAC } \\
\text { Agg gAg CAA g-3' } \\
5^{\prime}-g C A \text { ACT CCT CAT } \\
\text { ggC TgA ggT CTC A- } \\
3^{\prime}\end{array}$ & 740 & $\begin{array}{l}\Pi 1 \\
\mathrm{GT} \\
\mathrm{GG}\end{array}$ & $515-225$ & $\begin{array}{l}\text { mut } \\
\text { ht } \\
\text { wt }\end{array}$ & Bsp120l & [45] \\
\hline $\begin{array}{l}C d x- \\
2\end{array}$ & Intron 1e & $\mathrm{G} / \mathrm{A}$ & $\begin{array}{l}C C \\
C C \\
C C\end{array}$ & $\begin{array}{l}\text { 5'-CAg CAT gCC TgT } \\
\text { CCT CAg C-3' } \\
\text { 5'-CCA gTA CTg CCA } \\
\text { gCT CCC-3' }\end{array}$ & 250 & $\begin{array}{l}\mathrm{AA} \\
\mathrm{GA} \\
\mathrm{GG}\end{array}$ & & $\begin{array}{l}\text { mut } \\
\text { ht } \\
\text { wt }\end{array}$ & Bpu10l & [47] \\
\hline
\end{tabular}




\section{Discussion}

Increasing evidences suggest a pivotal role for vitamin $\mathrm{D}$ in insulin action $[15,16]$ and T2DM $[12,13]$. However, the results of vitamin D supplementation in diabetics have not been consistent $[20,25]$. The reasons for this inconsistency could be the vitamin D dosage and route of administration (injection [27,28] vs. oral [30]), age of the study population (middle aged [49] vs. elderly [50]) and probably genetic variations. The role of VDR polymorphism in response to vitamin $\mathrm{D}$ interventions has been reported in other clinical settings [51,52]. The contribution of VDR polymorphism in susceptibility to T2DM has also been shown in some studies recently [18]. However, this is the first clinical trial on the role of VDR polymorphism in response to vitamin D replenishment on different aspects of diabetic pathology, including anthropometric, metabolic, oxidative stress, inflammatory and immunity. This study pursues three objectives: Firstly, to tackle relationship between VDR genotypes and T2DM for the first time in Iranian population; secondly, to elucidate the potential mechanisms and cross-talk among pathways, by which vitamin $\mathrm{D}$ exerts its effects on diabetes, insulin resistance and cardiovascular disease by evaluating an extensive panel of biomarkers (anthropometric, metabolic, inflammatory and oxidative stress); and finally to identify vitamin D responsive vs. less or (maybe) non-responsive VDR genetic variants in subjects with T2DM for further proper nutritional care.

The following points can be considered as the strengths of this study: i) the intervention is conducted during cold seasons, when dermal synthesis, especially at Tehran latitude, is minimal[53]; ii) various degrees of vitamin D deficiency have been shown to be prevalent in Iranian general population at almost all ages [54] as well as diabetics [21]. Because of lower basal 25(OH)D levels, the response to vitamin $\mathrm{D}$ replenishment is expected to be more prominent; iii) yogurt drink, a popular Iranian drink, is used to fortify with vitamin D for the first time. The results of this study will show the bioavailability of vitamin D in this drink. Moreover, apart from the added vitamin $\mathrm{D}$, yogurt drink protein and calcium content makes it a very good choice and a substitute for sugarfree colas and even juices in diabetic, as well as a variety of non-diabetic, diets; iv) the dosage of vitamin D [55] and duration of intervention [56] seem to be proper.

The present study, at least in part, elucidates the discrepancies in the results of different vitamin D-diabetes studies pertaining to the genetic variations of the population. On the other hand, the importance of the upcoming results lies on the fact that both metabolic syndrome and obesity-induced insulin resistance, two conditions with increasing global occurrences which predispose T2DM development [33], have similar pathologic bases [34]. If VDR SNPs are found to influence the response to our intervention, then knowing distribution of VDR polymorphisms in both diabetic and non-diabetic populations can give a picture of the proportion of the community in whom up to $1000 \mathrm{IU} / \mathrm{d}$ vitamin D may not be effective enough to improve insulin resistance and related morbidities. Therefore, they should ideally receive further nutritional support according to their genotype.

\section{Abbreviations}

BLAST: basic local alignment search tool; BP: blood pressure; BMI: body mass index; CVD: cardiovascular disease; CL: chemiluminesence; CPBA: competitive protein binding assay; DNA: deoxyribonucleic acid; EIA: enzyme linked immune assay; EDTA: ethylene diamine tetra-acetate; FSG: fasting serum glucose; FYD: fortified yogurt drink; HDL-C: high density cholesterol; ht: heterozygote mutated; HPLC: high-performance liquid chromatography; hsCRP: highly sensitive C-reactive protein; iPTH: intact parathyroid hormone; IFN-gamma: Interferon-gamma; IL-4/IL-10/IL-6/LL-2: Interleukin 4/Interleukin 10/Interleukin-6/Interleukin-2; LPS: lipopolysaccharide; LDL-C: low density lipoprotein cholesterol; MDA: malondialdeyde; mut: homozygote mutated; NNFTRI: national nutrition and food technology research institute; PHA: phytohemmaglutinin; PYD: plain yogurt drink; PCR: polymerase chain reaction; RIA: radioimmunoassay; RCT: randomized clinical trial; RFLP: restriction fragment length polymorphism; sqFFQ: semi-quantitative Food Frequency Questionnaire; SNP: single nucleotide polymorphism; TUMS: Tehran University of medical sciences; TG: triglycerides; TNF: tumor necrosis factor; T2DM: type 2 diabetes mellitus; WC: waist circumference; Wt: homozygote wild type

\section{Acknowledgements}

We thank the Iranian Diabetic Society and Gabric Diabetic society for their collaborations. They have no role in study design, data collection, synthesis and interpretation, writing the report, or the decision to submit the manuscript for publication. This study is funded by NNFTRI, TUMS and Iran National Science Foundation, in order of their financial contributions. INSF had no role in the study conception or design. Half of the yogurt drinks (both plain and vitamin D-fortified) was dedicated by Pegah Company to the researchers while the remainder was purchased from there.

\section{Author details}

${ }^{1}$ Department of Nutrition and Biochemistry, School of Public Health, Tehran University of Medical Sciences (TUMS), Tehran, Iran. ${ }^{2}$ Laboratory of Nutrition Research, National Research Institute and Faculty of Nutrition and Food Technology; Shahid Beheshti University of Medical Sciences (SBUM), Tehran, Iran.

\section{Authors' contributions}

TRN designed the initial idea of this work, which was further developed by SSh and ADj. Now, this is a common project between NNFTRI and TUMS, the most part of which is being done as Ph.D. research of SSh under the supervision of both TRN and ADj. The manuscript has been read and approved by all authors.

\section{Competing interests}

The authors declare that they have no competing interests.

Received: 24 March 2011 Accepted: 22 June 2011

Published: 22 June 2011

\section{References}

1. Economic consequences of diabetes mellitus in the U.S. in 1997. In Diabetes Care. Volume 21. American Diabetes Association; 1998:(2):296-309.

2. Narayan KM, Boyle JP, Thompson TJ, Sorensen SW, Williamson DF: Lifetime risk for diabetes mellitus in the United States. Jama 2003, 290(14):1884-1890 
3. Hamman RF: Genetic and environmental determinants of non-insulindependent diabetes mellitus (NIDDM). Diabetes Metab Rev 1992, 8(4):287-338.

4. Jin W, Patti ME: Genetic determinants and molecular pathways in the pathogenesis of Type 2 diabetes. Clin Sci (Lond) 2009, 116(2):99-111.

5. Gillies PJ: Nutrigenomics: the Rubicon of molecular nutrition. J Am Diet Assoc 2003, 103(12 Suppl 2):S50-55.

6. Schork NJ, Fallin D, Lanchbury JS: Single nucleotide polymorphisms and the future of genetic epidemiology. Clin Genet 2000, 58(4):250-264.

7. Barroso I, Luan J, Middelberg RP, Harding AH, Franks PW, Jakes RW, Clayton D, Schafer AJ, O'Rahilly S, Wareham NJ: Candidate gene association study in type 2 diabetes indicates a role for genes involved in beta-cell function as well as insulin action. PLOS Biol 2003, 1(1):E20.

8. Krishnan AV, Trump DL, Johnson CS, Feldman D: The role of vitamin D in cancer prevention and treatment. Endocrinol Metab Clin North Am 2010, 39(2):401-418, table of contents.

9. Kamen $\mathrm{DL}$, Tangpricha $\mathrm{V}$ : Vitamin $\mathrm{D}$ and molecular actions on the immune system: modulation of innate and autoimmunity. J Mol Med 2010, 88(5):441-450.

10. Reis $A F$, Hauache $O M$, Velho G: Vitamin D endocrine system and the genetic susceptibility to diabetes, obesity and vascular disease. A review of evidence. Diabetes Metab 2005, 31(4 Pt 1):318-325.

11. Martini LA, Wood RJ: Vitamin D status and the metabolic syndrome. Nutr Rev 2006, 64(11):479-486.

12. Palomer X, Gonzalez-Clemente JM, Blanco-Vaca F, Mauricio D: Role of vitamin $\mathrm{D}$ in the pathogenesis of type 2 diabetes mellitus. Diabetes Obes Metab 2008, 10(3):185-197.

13. Mathieu C, Badenhoop K: Vitamin D and type 1 diabetes mellitus: state of the art. Trends Endocrinol Metab 2005, 16(6):261-266.

14. Gregori S, Giarratana N, Smiroldo S, Uskokovic M, Adorini L: A 1alpha,25dihydroxyvitamin $D(3)$ analog enhances regulatory T-cells and arrests autoimmune diabetes in NOD mice. Diabetes 2002, 51(5):1367-1374.

15. Kadowaki $S$, Norman AW: Dietary vitamin D is essential for normal insulin secretion from the perfused rat pancreas. J Clin Invest 1984, 73(3):759-766.

16. Gedik $\mathrm{O}$, Akalin $\mathrm{S}$ : Effects of vitamin $\mathrm{D}$ deficiency and repletion on insulin and glucagon secretion in man. Diabetologia 1986, 29(3):142-145.

17. Avenell A, Cook JA, MacLennan GS, McPherson GC: Vitamin D supplementation and type 2 diabetes: a substudy of a randomised placebo-controlled trial in older people (RECORD trial, ISRCTN 51647438). Age Ageing 2009, 38(5):606-609.

18. Schwalfenberg G: Vitamin $D$ and diabetes: improvement of glycemic control with vitamin D3 repletion. Can Fam Physician 2008, 54(6):864-866.

19. Schleithoff SS, Zittermann A, Tenderich G, Berthold HK, Stehle P, Koerfer R: Vitamin $D$ supplementation improves cytokine profiles in patients with congestive heart failure: a double-blind, randomized, placebo-controlled trial. Am J Clin Nutr 2006, 83(4):754-759.

20. Pittas AG, Harris SS, Stark PC, Dawson-Hughes B: The effects of calcium and vitamin D supplementation on blood glucose and markers of inflammation in nondiabetic adults. Diabetes Care 2007, 30(4):980-986.

21. Neyestani T, Gharavi A, Kalayi A: Iranian diabetics may not be Vitamin D deficient more than healthy subjects. Acta Medica Iranica 2008, 46(4).

22. Campbell IT, Jarrett RJ, Keen H: Diurnal and seasonal variation in oral glucose tolerance: studies in the Antarctic. Diabetologia 1975, 11(2):139-145.

23. Gikas A, Sotiropoulos A, Pastromas V, Papazafiropoulou A, Apostolou O, Pappas S: Seasonal variation in fasting glucose and $\mathrm{HbA1c}$ in patients with type 2 diabetes. Prim Care Diabetes 2009, 3(2):111-114.

24. Parekh D, Sarathi V, Shivane VK, Bandgar TR, Menon PS, Shah NS: Pilot study to evaluate the effect of short-term improvement in vitamin D status on glucose tolerance in patients with type 2 diabetes mellitus. Endocr Pract 2010, 16(4):600-608.

25. Patel $P$, Poretsky $L$, Liao E: Lack of effect of subtherapeutic vitamin $D$ treatment on glycemic and lipid parameters in Type 2 diabetes: A pilot prospective randomized trial. J Diabetes 2010, 2(1):36-40.

26. Bid HK, Konwar R, Aggarwal CG, Gautam S, Saxena M, Nayak VL, Banerjee M: Vitamin D receptor (Fokl, Bsml and Taql) gene polymorphisms and type 2 diabetes mellitus: a North Indian study. Indian J Med Sci 2009, 63(5):187-194.

27. Boucher BJ, Mannan N, Noonan K, Hales CN, Evans SJ: Glucose intolerance and impairment of insulin secretion in relation to vitamin $D$ deficiency in east London Asians. Diabetologia 1995, 38(10):1239-1245.
28. Taylor AV, Wise PH: Vitamin D replacement in Asians with diabetes may increase insulin resistance. Postgrad Med J 1998, 74(872):365-366.

29. Isaia $G$, Giorgino R, Adami S: High prevalence of hypovitaminosis $D$ in female type 2 diabetic population. Diabetes Care 2001, 24(8):1496.

30. Borissova AM, Tankova T, Kirilov G, Dakovska L, Kovacheva R: The effect of vitamin D3 on insulin secretion and peripheral insulin sensitivity in type 2 diabetic patients. Int J Clin Pract 2003, 57(4):258-261.

31. Allegra V, Luisetto G, Mengozzi $G$, Martimbianco L, Vasile A: Glucoseinduced insulin secretion in uremia: role of 1 alpha,25(HO)2-vitamin D3. Nephron 1994, 68(1):41-47.

32. Sadighi J, Sheikholeslam R, Mohammad K, Pouraram H, Abdollahi Z, Samadpour K, Kolahdooz F, Naghavi M: Flour fortification with iron: a midterm evaluation. Public Health 2008, 122(3):313-321.

33. Nichols GA, Moler EJ: Metabolic Syndrome Components Are Associated with Future Medical Costs Independent of Cardiovascular Hospitalization and Incident Diabetes. Metab Syndr Relat Disord 2010.

34. Halpern A, Mancini MC, Magalhaes ME, Fisberg M, Radominski R, Bertolami MC, Bertolami A, de Melo ME, Zanella MT, Queiroz MS, et al: Metabolic syndrome, dyslipidemia, hypertension and type 2 diabetes in youth: from diagnosis to treatment. Diabetol Metab Syndr 2010, 2:55.

35. Tangpricha V, Koutkia P, Rieke SM, Chen TC, Perez AA, Holick MF: Fortification of orange juice with vitamin $D$ : a novel approach for enhancing vitamin D nutritional health. Am J Clin Nutr 2003, 77(6):1478-1483

36. Bantle JP, Wylie-Rosett J, Albright AL, Apovian CM, Clark NG, Franz MJ, Hoogwerf BJ, Lichtenstein AH, Mayer-Davis E, Mooradian AD, et al: Nutrition recommendations and interventions for diabetes: a position statement of the American Diabetes Association. Diabetes Care 2008, 31(Suppl 1):S61-78.

37. Vieth R, Bischoff-Ferrari H, Boucher BJ, Dawson-Hughes B, Garland CF, Heaney RP, Holick MF, Hollis BW, Lamberg-Allardt C, MCGrath JJ, et al: The urgent need to recommend an intake of vitamin $\mathrm{D}$ that is effective. Am J Clin Nutr 2007, 85(3):649-650.

38. Hollis BW: Circulating 25-hydroxyvitamin D levels indicative of vitamin D sufficiency: implications for establishing a new effective dietary intake recommendation for vitamin D. J Nutr 2005, 135(2):317-322.

39. Katz A, Nambi SS, Mather K, Baron AD, Follmann DA, Sullivan G, Quon MJ: Quantitative insulin sensitivity check index: a simple, accurate method for assessing insulin sensitivity in humans. J Clin Endocrinol Metab 2000, 85(7):2402-2410

40. Neyestani TR, Gharavi A, Kalayi A: Determination of serum 25-hydroxy cholecalciferol using high-performance liquid chromatography: a reliable tool for assessment of vitamin D status. Int I Vitam Nutr Res 2007, 77(5):341-346.

41. Neyestani TR, Fereydouni Z, Hejazi S, Salehi-Nasab F, Nateghifard F, Maddah M, Karandish M: Vitamin C status in Iranian children with acute lymphoblastic leukemia: evidence for increased utilization. J Pediatr Gastroenterol Nutr 2007, 45(1):141-144.

42. Satoh K: Serum lipid peroxide in cerebrovascular disorders determined by a new colorimetric method. Clin Chim Acta 1978, 90(1):37-43.

43. Neyestani TR, Shariatzadeh N, Gharavi A, Kalayi A, Khalaji N: Physiological dose of lycopene suppressed oxidative stress and enhanced serum levels of immunoglobulin $M$ in patients with Type 2 diabetes mellitus: a possible role in the prevention of long-term complications. J Endocrinol Invest 2007, 30(10):833-838.

44. Neyestani TR, Gharavi A, Kalayi A: Selective effects of tea extract and its phenolic compounds on human peripheral blood mononuclear cell cytokine secretions. Int J Food Sci Nutr 2009, 60(Suppl 1):79-88.

45. Deng HW, Shen H, Xu FH, Deng HY, Conway T, Zhang HT, Recker RR: Tests of linkage and/or association of genes for vitamin $D$ receptor, osteocalcin, and parathyroid hormone with bone mineral density. J Bone Miner Res 2002, 17(4):678-686.

46. Ye WZ, Reis AF, Velho G: Identification of a novel Tru9 I polymorphism in the human vitamin D receptor gene. J Hum Genet 2000, 45(1):56-57.

47. Liu PY, Zhang YY, Lu Y, Long JR, Shen $H$, Zhao LJ, Xu FH, Xiao P, Xiong DH, Liu YJ, et al: A survey of haplotype variants at several disease candidate genes: the importance of rare variants for complex diseases. J Med Genet 2005, 42(3):221-227.

48. Purcell S, Daly MJ, Sham PC: WHAP: haplotype-based association analysis. Bioinformatics 2007, 23(2):255-256. 
49. Bonjour JP, Benoit V, Pourchaire O, Ferry M, Rousseau B, Souberbielle JC: Inhibition of markers of bone resorption by consumption of vitamin $D$ and calcium-fortified soft plain cheese by institutionalised elderly women. Br J Nutr 2009, 102(7):962-966.

50. Johnson JL, Mistry W, Vukovich MD, Hogie-Lorenzen T, Hollis BW, Specker BL: Bioavailability of vitamin D from fortified process cheese and effects on vitamin D status in the elderly. J Dairy Sci 2005, 88(7):2295-2301.

51. Arabi A, Zahed L, Mahfoud Z, El-Onsi L, Nabulsi M, Maalouf J, Fuleihan Gel H: Vitamin D receptor gene polymorphisms modulate the skeletal response to vitamin D supplementation in healthy girls. Bone 2009, 45(6):1091-1097.

52. Fu L, Yun F, Oczak M, Wong BY, Vieth R, Cole DE: Common genetic variants of the vitamin $D$ binding protein (DBP) predict differences in response of serum 25 -hydroxyvitamin $D[25(\mathrm{OH}) \mathrm{D}]$ to vitamin $\mathrm{D}$ supplementation. Clin Biochem 2009, 42(10-11):1174-1177.

53. Lagunova Z, Porojnicu AC, Lindberg F, Hexeberg S, Moan J: The dependency of vitamin $D$ status on body mass index, gender, age and season. Anticancer Res 2009, 29(9):3713-3720.

54. Hashemipour S, Larijani B, Adibi H, Javadi E, Sedaghat M, Pajouhi M, Soltani A, Shafaei AR, Hamidi Z, Fard AR, et al: Vitamin D deficiency and causative factors in the population of Tehran. BMC Public Health 2004, 4:38.

55. Clements MR, Davies M, Hayes ME, Hickey CD, Lumb GA, Mawer EB, Adams PH: The role of 1,25-dihydroxyvitamin $D$ in the mechanism of acquired vitamin D deficiency. Clin Endocrinol (OXf) 1992, 37(1):17-27.

56. Vieth R: Vitamin D supplementation, 25-hydroxyvitamin D concentrations, and safety. Am J Clin Nutr 1999, 69(5):842-856.

\section{Pre-publication history}

The pre-publication history for this paper can be accessed here: http://www.biomedcentral.com/1472-6823/11/12/prepub

doi:10.1186/1472-6823-11-12

Cite this article as: Shab-Bidar et al: Efficacy of vitamin D3-fortifiedyogurt drink on anthropometric, metabolic, inflammatory and oxidative stress biomarkers according to vitamin $\mathrm{D}$ receptor gene polymorphisms in type 2 diabetic patients: a study protocol for a randomized controlled clinical trial. BMC Endocrine Disorders 2011 11:12.

\section{Submit your next manuscript to BioMed Central and take full advantage of:}

- Convenient online submission

- Thorough peer review

- No space constraints or color figure charges

- Immediate publication on acceptance

- Inclusion in PubMed, CAS, Scopus and Google Scholar

- Research which is freely available for redistribution

Submit your manuscript at www.biomedcentral.com/submit 